en la discusión de la comunidad científica de los constitucionalistas. Creo que he sido lo bastante claro para plantear el problema en toda su crudeza, tal y como yo lo veo.

\title{
MANUEL SÁNCHEZ DE DIEGO
}

Ha sido usted extraordinariamente exquisito. Estamos aquí dos docenas de personas, y discrepo ligeramente con D. Juan Cano. Aquí ha habido una reforma constitucional encubierta con una quiebra de la Constitución, por medio de la reforma de los Estatutos de Autonomía.. No veo claro, a mi juicio, que dentro de la materia estatutaria puedan incluirse derechos fundamentales autonómicos.Con más razones se podía haber incluido en los Estatutos la relación de puestos de trabajo de la Comunidad Autónoma. Ese es el punto de discrepancia más importante. Creo que el principio de igualdad y el principio de libertad son para todos los españoles en todo el territorio español. Otra cuestión es que la Comunidad Autónoma quiera solucionar al problema de la vivienda en su Comunidad Autónoma, pero yo creo que eso no es materia estatutaria. Y , por último, estoy totalmente de acuerdo con el profesor Portero, en el sentido de que esto no se va a exigir, salga como salga la resolución del Tribunal Constitucional en los recurso de los Estatutos de Autonomía, nos va a exigir una reforma constitucional.

\section{COMISIÓN SOBRE LA APLICACIÓN JUDICIAL DEL DERECHO CONSTITUCIONAL ${ }^{5}$}

\author{
MANUEL JIMÉNEZ DE PARGA
}

Buenas tardes, señoras y señores.

Esta Comisión va a versar sobre aplicación judicial del Derecho Constitucional. Conmigo están en la mesa los tres ponentes que durante diez, quince minutos, van a exponer sus ideas al respecto sin perjuicio de que luego iniciemos el correspondiente debate.

En primer término, el profesor Gómez Montoro, junto a mi derecha, va a desarrollar su ponencia sobre la aplicación judicial del Derecho Constitucional. Ángel, cuando quieras.

5 A esta Comisión presentó comunicación la Prof ${ }^{a}$. Ma Luz Martínez Alarcón bajo la rúbrica "La aplicación judicial del derecho Constitucional". 


\section{ÁNGEL GÓMEZ MONTORO}

Muchas gracias don Manuel.

Quiero agradecer brevemente a los organizadores —-brevemente por el tiempo, no por la sinceridad del agradecimiento- la invitación a participar en esta Mesa redonda y felicitarles por la organización de esta jornada que nos ha permitido — nos está permitiendo— reunirnos hoy y reflexionar sobre estos temas más generales de nuestra disciplina, a los que no siempre es fácil dedicarle tiempo.

Pienso que, al igual que en las sesiones de esta mañana, no se espera de los ponentes una exposición completa y cerrada del tema que se nos ha adjudicado (lo que por otra parte sería imposible en el tiempo de que disponemos) sino que, más bien, se trata de poner sobre la mesa algunos temas, algunos problemas o cuestiones sobre las que debatir.

Cuando recibí la invitación a participar en esta Jornada tenía dudas, que no despejé — quizás culpablemente-, de si debía hablar del Derecho Constitucional como parte del ordenamiento o del Derecho Constitucional como saber. Pienso que desde ambos enfoques se pueden plantear algunas cuestiones interesantes en relación con la aplicación judicial. Me voy a centrar inicialmente en la primera perspectiva, aunque luego querría decir también algo de lo segundo, es decir del Derecho Constitucional como disciplina que reflexiona sobre esa rama del ordenamiento jurídico.

Y me quería centrar básicamente en tres puntos, que expongo de manera muy sucinta.

La normatividad de la Constitución ha potenciado su aplicación judicial a la vez que ésta refuerza ese carácter normativo

La primera realidad que se constata en estos casi treinta años de Constitución es que su carácter normativo, proclamado taxativamente por la propia Norma fundamental, pero también por la jurisprudencia constitucional y por la doctrina, ha potenciado la aplicación judicial del Derecho Constitucional. Me parece que esto es algo incuestionable. Esta mañana debatíamos sobre la metodología de nuestra disciplina, sobre si debe estar más presente la aplicación práctica o enfoques que pongan más el énfasis en la teoría general del Derecho Constitucional, la Historia o la Ciencia Política, por citar algunos casos. Al margen de otras consideraciones en las que ahora que no puedo detenerme, lo cierto es que resulta evidente que el Derecho Constitucional, la Constitución, es hoy $-\mathrm{y}$ viene siéndolo desde su promulgación - objeto de aplicación por los órganos jurisdiccionales en todos los niveles.

Durante los primeros años fue sobre todo el Tribunal Constitucional el que desplegó en sus sentencias toda la fuerza normativa del texto constitucional; y pienso que todos recibimos aquellas sentencias con un gran interés, hasta el punto de que se ha podido denunciar - no sin algo de razón - un cierto seguidismo de los constitucionalistas respecto de la jurisprudencia constitucional; buena parte de nuestros esfuerzos se centró en los comentarios de sentencias, y las referencias jurisprudenciales han estado presentes en todos los trabajos sobre los distintos aspectos de la Constitución. 
Pero la Constitución fue también enseguida objeto de aplicación tanto por el Tribunal Supremo como por los demás jueces y tribunales integrantes del poder judicial. Se ha insistido no pocas veces en el temor que podía existir en el momento de aprobación de la Constitución sobre la actuación del poder judicial. El caso es que, quitando contadas excepciones, éste asumió de manera natural su nuevo papel como intérprete, aplicador y garante — desde luego no último pero sí muy relevante- de la Norma fundamental. Y cada vez tiene mayor trascendencia, como es bien sabido, la jurisprudencia del Tribunal Europeo de Derechos Humanos que, aunque no se refiera directamente a la aplicación de la Constitución, es sin embargo muy relevante para la misma en la medida en que viene a concretar determinadas interpretaciones de los derechos fundamentales que se imponen a los Tribunales internos.

Y quisiera también poner de relieve que la aplicación judicial de la Constitución por los tribunales ordinarios, si bien se produce primordialmente en el ámbito de los derechos fundamentales, afecta también en otros ámbitos del Derecho Constitucional como por ejemplo las fuentes del Derecho o la organización territorial del Estado. Quizá tenga menor relevancia a la organización funcional del poder, aunque ésta ha sido también objeto de controversias jurídicas que han dado lugar a resoluciones jurisdiccionales.

\section{Algunas dificultades que suscita la aplicación judicial de la Constitu- ción}

Como acabo de señalar, la aplicación judicial del Derecho Constitucional es necesaria y desde luego imprescindible, pero también introduce algunas dificultades.

La primera de ellas es la mayor imprevisibilidad de las soluciones de controversias en las que se aplican preceptos constitucionales. No puedo detenerme en cuestiones que, por otra parte, son bien conocidas: el carácter abierto de los preceptos constitucionales, los métodos de resolución de conflictos típicos del Derecho Constitucional (la ponderación, razonabilidad, proporcionalidad...), las dificultades metodológicas que su aplicación presenta, etc. Pero creo que es un hecho generalmente admitido que estas dificultades llevan en no pocas ocasiones, o en todo caso en más ocasiones de las deseables, a soluciones insatisfactorias que contrastan con la previsibilidad que cabe esperar de las decisiones judiciales. Si de todo Derecho se espera que pacifique controversias jurídicas, en el caso del Derecho Constitucional esa función pacificadora tiene una especial trascendencia. Y en no pocas ocasiones la sensación que producen las soluciones adoptadas — por ejemplo en materia de organización territorial o en el ámbito de los derechos fundamentales- es de poca previsibilidad y, por tanto, de un cierre sólo provisional de los problemas.

Se trata de una sensación que a veces alcanza a quienes nos dedicamos al Derecho Constitucional pero que, con mucho más motivo, trasciende a la opinión pública: la sensación de que no se sabe cómo va a terminar un pleito cuando entran en juego las cláusulas abiertas de la Constitución, cuando por ejemplo está por medio el concepto de honor o de intimidad o cuando debe resolverse definiendo cuáles son las bases sobre una determinada materia. Este ca- 
rácter abierto de los preceptos aporta, lo sabemos muy bien, flexibilidad; tiene, por ello, sus ventajas, pero también presenta inconvenientes. Y a la larga puede, de alguna manera, disminuir o minar la legitimidad de las decisiones, sembrar dudas sobre la propia cientificidad de la interpretación constitucional, del acercamiento a la Constitución y en última instancia de nuestra propia disciplina.

Es verdad que esto no ocurre sólo con el Derecho Constitucional, y por ello no hay que exagerar las cosas. Y en parte creo que es algo con lo que hay que acostumbrarse a convivir. Pero quizá convendría profundizar en la búsqueda de parámetros más firmes y, junto a ello porque muchas veces los parámetros existen exigir mayor rigor en su aplicación. A veces se tiene la sensación de que hemos ido incorporando formas de actuación típicas del case law, del Derecho de los casos concretos, pero sin incorporar los mecanismos de los que dispone el Derecho americano para garantizar la previsibilidad, y estoy pensando, por ejemplo, en la técnica del precedente. Creo que sería importante avanzar en la definición de esos tests o cánones de control claros que, además, deberían ser siempre aplicados con rigor. No se me oculta que, por muy bien que se aplique el método de la ponderación o el principio de proporcionalidad, puede haber dudas sobre la solución concreta; pero parece necesario llevar hasta el final todos los pasos, exteriorizar los razonamientos en la propia resolución judicial, de manera que se vea el esfuerzo por llevar el razonamiento jurídico hasta las últimas consecuencias. En no pocas ocasiones se echa de menos un análisis más riguroso, una aplicación más ajustada a los hechos y razonamientos jurídicos más aquilatados que eviten la sensación de que se está decidiendo más a base de voluntad de que razón.

Pienso, por ejemplo, en los típicos conflictos entre libertad de expresión o información y el derecho al honor, o a la intimidad. No es extraño que las cuatro instancias que normalmente se pronuncian (las tres de la jurisdicción ordinaria, más el Tribunal Constitucional), aporten soluciones diferentes, y ello de manera muy razonaba, aunque en ocasiones se tiene también la sensación de estar ante decisiones un tanto voluntaristas.

Es necesario, por tanto resolver el caso concreto -y me parece que esa proximidad al caso le aporta al Derecho Constitucional aspectos muy interesantes-; pero es necesario partir siempre de las categorías generales y desde luego reforzar el respeto al tenor de la norma que, en no pocas ocasiones, y so capa de la mencionada flexibilidad, se ve forzado atendidas las circunstancias del caso. O en ocasiones se fuerza ese tenor en aras a las presuntas exigencias de una realidad social más o menos difusa. Es evidente que la aplicación del Derecho Constitucional tiene que hacerse atendiendo a la realidad social, que, de alguna manera, debe integrarse en el ámbito normativo de los preceptos constitucionales. Pero en esa tensión entre adaptación de la Constitución a la realidad social y respeto al tenor literal no se si consigue siempre el equilibrio deseable. Creo que en aras a la mencionada previsibilidad, se precisa a veces perder flexibilidad y ganar en certeza.

Necesidad de tener en cuenta el tipo de Tribunal y de proceso en el que se produce la aplicación del precepto constitucional 
Un tercer problema que plantea la aplicación judicial del Derecho Constitucional o que al menos puede plantearse (y sobre esto no se si ha hecho una adecuada reflexión), es la importancia de tomar en consideración el tipo de tribunal y de proceso en el que se hace la interpretación de un determinado contenido de la Constitución y me refiero ahora especialmente al ámbito de los derechos fundamentales. Y es que no es extraño que la interpretación del contenido protegido por el derecho venga condicionada por el tipo de proceso y por el tipo de Tribunal que se pronuncia. Así, por ejemplo, cuando el Tribunal Constitucional, interpretando el derecho a la tutela judicial efectiva del art. 24.1 CE, dice que no garantiza el acierto de las resoluciones judiciales, creo que lo que en realidad está diciendo es que él no puede garantizar ese acierto en la aplicación de la legalidad (pues no es una tercera instancia), lo que no es exactamente lo mismo que decir que el acierto en las resoluciones judiciales no tiene nada que ver con el derecho a la tutela judicial. Algo similar ocurre con el derecho a la igualdad en la aplicación de la ley: cuando dos órganos judiciales aplican de manera desigual la misma norma a los mismos hechos, no es que no esté en juego el derecho a la igualdad (que pretende precisamente decisiones desiguales en supuestos idénticos); lo que en realidad dice el Tribunal Constitucional al indicar que no se ha vulnerado el art. $14 \mathrm{CE}$ es que él no es el tribunal idóneo para reparar esa desigualdad en la aplicación de la norma.

Esto que sucede en el Tribunal Constitucional también ocurre con el Tribunal Europeo de Derechos Humanos que, en ocasiones, reconducen a determinados derechos fundamentales unos contenidos que de entrada no parecen fácilmente identificables dentro del ámbito garantizado por los mismos. Estoy pensando, por ejemplo, en la protección medioambiental a través del derecho a la privacidad, una doctrina que conoce bien el profesor Jiménez de Parga. Pienso que la decisión de incluir esos nuevos contenidos viene condicionada en buena medida por la vía de protección y por la posición que asume el Tribunal Europeo de Derechos Humanos. A él le corresponde asegurar la protección de los derechos del Convenio por parte de los Estados miembro y para él es en buena medida indiferente que éstos lo hagan mediante la aplicación de un derecho fundamental, acudiendo a un derecho subjetivo no fundamental o a través de Derecho objetivo que traspone o concreta un mandato constitucional de protección (por ejemplo del medioambiente). Lo relevante es si se produce o no la tutela exigida por el Convenio y de aquí que la no protección se traduzca en infracción. Sin embargo, cuando se trata de tribunales internos es muy relevante decidir si un determinado bien está protegido por el derecho fundamental o si la tutela deriva de un mandato al legislador que debe establecer los cauces de protección. Ocurre, sin embargo, que, cuando hay que hacerse eco de la doctrina del Tribunal de Estrasburgo, esos matices se olvidan y no pocas veces se hacen traslaciones in totum.

Aplicación de la Constitución y enseñanza del Derecho Constitucional

Estos son algunos de los problemas que me sugería el tema de esta mesa redonda. Pero, como señalaba al principio, no quiero terminar sin hacer alguna reflexión sobre la incidencia de aplicación judicial de la Constitución en la en- 
señanza del Derecho Constitucional. Y es que entiendo que esa eficacia normativa de la Norma fundamental es algo muy relevante también para la docencia de nuestra disciplina. Me parece que todos nosotros, a la hora de enseñar el Derecho Constitucional, tenemos muy en cuenta esa trascendencia práctica. De aquí la importancia del análisis de casos, pero no como mera formación práctica, sino como la mejora manera $-\mathrm{O}$ al menos como un instrumento imprescindible - de entender la teoría.

Mi experiencia es que, cada vez más, el caso práctico es necesario, no para que los alumnos sepan los plazos o conozcan las decisiones judiciales, sino para que comprendan, por ejemplo, la eficacia de los derechos en las relaciones privadas, que sólo se entienden bien cuando se examinan en el ámbito de un problema concreto; o para que entiendan en qué consiste la ponderación o el principio de proporcionalidad.

Es verdad que la docencia pegada al caso tiene también algunos riesgos. Y ahora transmito una inquietud más que otra cosa: la insistencia en que lo importante a la hora de resolver el caso es la forma de razonar y no tanto las soluciones concretas, puede llevar a trasmitir una visión un tanto subjetiva del razonamiento jurídico. Que en Derecho caben soluciones diferentes al mismo problema es una realidad que tienen que conocer los estudiantes, pero en línea con lo antes apuntado, es necesario hacerles ver que no todo es subjetivo, que es necesario aplicar las técnicas metodológicas con rigor, agotando los razonamientos. Y con esto termino, aunque no sin agradecer su paciencia y pedir disculpas por la excesiva síntesis a la hora de abordar los temas.

\section{MANUEL JIMÉNEZ DE PARGA}

Muchas gracias al profesor Gómez Montoro por su exposición y haber respetado las instrucciones que ha recibido sobre el horario, dado que tenemos que ser muy estrictos en el cumplimiento de nuestras normas y el tiempo que dedicamos. Ahora tiene la palabra el profesor Miguel Revenga Sánchez.

\section{MIGUEL REVENGA SÁNCHEZ}

Es un honor y una responsabilidad grande dirigirme desde esta Mesa a eminentes colegas y amigos con larga experiencia en la enseñanza e investigación del Derecho constitucional. De manera que no aspiro a decir nada nuevo; simplemente invoco aquello — aquí más verdad que nunca- de que si quieres aburrir, cuéntalo todo. No es preciso contar todo, porque cuando uno habla a colegas, sabe que la cortesía exige usar, y hasta abusar, del sobreentendido. Así que simplemente traeré aquí algunas reflexiones, no del todo hilvanadas, sobre la cuestión que nos convoca en esta Jornada, y en esta Mesa. Y la primera que se me ocurre es que, cuando se habla de aplicación judicial del Derecho Constitucional, casi se está diciendo una perogrullada e incurriendo en 
la tautología: el Derecho Constitucional dejó de ser aquel vaporoso Derecho Político que fue en otro tiempo, porque tiene aplicación judicial. No entro en si ello supuso mero maquillaje, o auténtica mudanza de naturaleza. Lo que quiero decir es que las raras veces en las que tenemos ocasión de poner en común nuestras reflexiones sobre el método, siempre acabamos diciendo que el Derecho Constitucional es Derecho y no otra cosa. ¿Y qué otra cosa podría ser? Con afirmaciones de ese carácter, que suenan como el peculiar mantra de nuestra disciplina, parece que expresamos la voluntad de reafirmarnos no se sabe frente a quién, el deseo de remover viejos complejos y el de terminar, de una vez por todas, con el déficit de juridicidad que acaso seguimos constatando. En realidad no es fácil saber cuál sea el sentido de tal reivindicación: si feliz constatación de normalidad frente a las turbulencias del pasado, si desideratum de espacio y estatuto académico, llamada a la sobriedad científica, o bien machacón recordatorio de una supuesta virtud jurídica oponible a las informalidades y exhuberancias de lo político. Seguramente de todo ello hay un poco, y no seré yo quien impugne la oportunidad y la conveniencia de un debate que, en último extremo, siempre permite interrogarse por los fundamentos de aquello que se explica en los programas docentes, y detenerse a evaluar cómo van las cosas de la política constitucional y qué le falta, en su caso, a la Constitución y al Derecho que versa sobre ella — ¿aplicación judicial? - para llegar a ser del todo lo que queremos que sea.

De lo que no cabe hablar ya, me parece, es de lo nuestro como un caso peculiar en el panorama comparado de la aplicación judicial de la Constitución. No es que España sea singularmente deficitaria en la aplicación judicial del Derecho Constitucional por razones históricas, sino que lo que ocurre aquí, como en todas partes, es que hemos tenido demasiada novedad en poco tiempo. El Derecho Constitucional que hoy explicamos (pero, sobre todo, el que aplicamos) es "nieto", por así decir, del proyecto revolucionario del que arranca la modernidad, pero recibe su impronta característica de un tiempo - al que me a mí me gusta llamar, para entendernos, el momento-Nüremberg - en el que se sientan las bases de un tipo de Constitución que poco tiene que ver con lo que había sido la Constitución hasta entonces. Con un factor adicional: esa gran novedad que supone el constitucionalismo de la posguerra está aún por teorizar con todas sus implicaciones y con todas sus consecuencias. No nos sirven las construcciones de la gran tradición positivista, en las que nos formamos muchos de nosotros, sencillamente porque en ellas los Códigos no dejaban espacio a la Constitución. Ni nos sirve, mal que les pese a quienes sucumben a los encantos de la auto-referencialidad científica, teoría pura alguna sobre la que fundamentar, y explicar, la necesidad de aplicación judicial de la Constitución. Kelsen abominaba de un tipo de Constitución como la que hoy tenemos; nada le disgustaba más que una Constitución cuya semántica se deslizara por los excelsos valores de la libertad y de la justicia, no porque no los compartiera, claro, sino porque los consideraba incompatibles con la racionalidad aplicativa del Derecho propia de los jueces. Si renunciamos al modelo explicativo Kelsen, aún aprovechando cierta técnica de control sobre la ley cuya paternidad le se- 
guimos atribuyendo, y lo que advertimos es un universo constitucional a la vez exigente (en cuanto que reclama cumplimiento de todo) y desordenado (en cuanto que reclama aplicación por todos), entonces el paradigma es más bien el de la Constitución re-materializada propia de lo que ya conocemos como neoconstitucionalismo, y el del Derecho que se moldea y acomoda al ritmo de una escala móvil de exigencias implícita al des-orden constitucional. Por echarle literatura al asunto: parece que hubiéramos renunciado a la rigidez de un $\mathrm{K}, \mathrm{y}$ hubiéramos entronizado la ductilidad de un $\mathrm{Z}$.

El neo-constitucionalismo es la etiqueta à la mode con la que intentamos captar y comprender la nueva situación: la de una Constitución-precipitado de principios (no siempre compatibles), sobrecargada de demandas, y disponible para encuadrar la gestión de los proyectos y expectativas más plurales. Bajo su fuerza directriz fluye un Derecho — que por desidia seguimos llamando "ordenamiento" - moldeable, en el que las trazas del legislador desvinculado y omnisciente han dejado paso a un juez bastante más poderoso de lo que nunca lo fue el propio autor de la ley. Pero con ello no se difumina ni pierde alcance la fuerza directriz de la Constitución; más bien ocurre el fenómeno inverso: ésta se hace omnipresente como telón de fondo para la resolución de los conflictos jurídicos. Y la presencia de la Constitución en el trasfondo de las cosas, y el ingreso de los derechos fundamentales en el corazón de los problemas, trastoca la aplicación judicial del Derecho, tomado en su conjunto: el método ya no se basa en mecánicas subsunciones de los hechos en las reglas, sino que consiste en operaciones ponderativas mediante las cuales el juez reordena los complejos urdimbres normativos a la luz de la Constitución. Se trata, en suma, de un sistema que ha acabado por hacer de todo juez un juez de —valdría más decir desde - la Constitución, y que ha entronizado a la Jurisdicción (específicamente) constitucional, como autora de la interpretación suprema de la Constitución en un lugar que recuerda al que antaño ocupaban los excelsos representantes de la voluntad general. Las bases del nuevo estado de cosas recibieron un impulso decisivo por obra del Tribunal Constitucional alemán, cuando comenzó a hablar de los derechos fundamentales como orden objetivo de valores y puso en pie toda la construcción en la que hoy nos encontramos. Normatividad de la Constitución, imperio de los principios (¿tiranía de los valores?), proscripción de la arbitrariedad de los poderes, y judicial review con la proporcionalidad como macro — criterio estándar de juicio, son hoy la señas de identidad del Estado con aplicación judicial de la Constitución, esto es, del Estado Constitucional, esto es, del Estado democrático

Por poco o mucho que nos guste la Constitución de los custodiadores, y por más o menos sensibles que seamos a los argumentos que reivindican el espacio del legislador democrático, creo que no hay alternativas. Y mucho menos en un país como el nuestro, donde no parece que haya motivos para lamentar lo mucho que se ha hecho en materia de aplicación judicial de la Constitución. La gran obsesión del poder constituyente fue remachar la juridicidad de la Constitución y establecer un sistema de justicia constitucional al que, un poco en broma, no es descabellado aplicarle esa denominación atrápalotodo con la 
que los politólogos etiquetan ciertos partidos. Necesitábamos una referencia, un canon último de certeza en manos del juez constitucional, y las cosas han salido razonablemente bien. El Tribunal Constitucional ha cumplido sobradamente las expectativas depositadas en él. Ha defendido la normatividad y la supraconstitucionalidad frente a viejos resabios, y a pesar de una tradición que era un erial. Ha encontrado el espacio justo, en decisiones señeras, frente al poder constituyente, frente al legislador, y frente al juez ordinario. Y se ha sumergido brillantemente, cuando la situación lo requería, en el mundo de las sentencias interpretativas, con esa diferencia entre norma como signo sensible y norma como mandato, que condensa por sí sola todas las variaciones que ha experimentado la teoría del Derecho por obra de la aplicación judicial de la Constitución. Por no hablar de las decisivas funciones reactivas, propedéuticas y dogmáticas en el ámbito de los derechos fundamentales, en el establecimiento de un sistema de fuentes de nueva planta, y en la gestión (re-constructiva) de una técnica constitucional de reparto territorial del poder literalmente inservible sin la contribución de un intérprete último en disposición de cerrarlo. Con el mero enunciado de las contribuciones realizadas en estos 25 años - aunque suene a discurso en exceso triunfalista y falto de mordiente crítica- no hay mucho más que añadir. Si de algo podemos lamentarnos, no creo que la obra del Tribunal Constitucional, tomada en su conjunto, pueda estar en el punto de mira. Si acaso, constataremos que "la ventana" del artículo 5 de la Ley Orgánica del Poder Judicial sigue estando en el origen de ciertos problemas y de cierta frustración de nuestras aspiraciones a una Constitución normativamente cumplida. Y puestos a hacer teoría y a revolver por los entresijos del método, quizá encontremos razones para denostar la sustitución del viejo positivismo de la teoría tradicional del Derecho, por un positivismo jurisprudencial a cuya luz no hay seguridad jurídica capaz de frenar la discrecionalidad del intérprete para justificar casi cualquier cosa.

Pero si las cosas son así, si el balance y el presente de la aplicación judicial de la Constitución no da razones para el desencanto, ¿a qué se debe cierta difusa sensación de crisis del modelo, o de "peligro claro y actual" para su subsistencia, y para la propia idea de Constitución normativa? Algo de ello he creído oír esta mañana en la intervención de Pedro Cruz, y me parece que es algo que no tiene que ver sólo con la guerra en la Corte, iniciada por un episodio de recusación que debió rechazarse a limine, sino que obedece a razones mucho más variadas y profundas. De entrada, tenemos el problema de la reforma de la Constitución. La difusión de la idea de que reformar nuestra Constitución es un imposible, socava gravemente su fuerza normativa, en la misma medida en que aumentan dentro de ella ámbitos de regulación sobrepasados por la realidad social, o que han devenido inservibles u obsoletos. Está además la recurrente cuestión de la sobrecarga de trabajo del Tribunal como consecuencia de una defectuosa articulación técnica de los cometidos de las jurisdicciones ordinaria y constitucional en el amparo de los derechos fundamentales, y señaladamente por lo que respecta al artículo 24 de la Constitución. Sinceramente no sabría decir si ello es producto de la incontinencia de abogados que no acaban de 
"empaparse" de jurisprudencia del intérprete supremo, o bien si el déficit de cultura constitucional está en el juez que adolece de miopía en la lectura de la ley según la Constitución interpretada. De todo habrá un poco. Y de paso, y a reglón seguido, me apresuro a añadir que no creo que podamos seguir lamentándonos de la existencia de dos mundos jurídicos escindidos, el "ordinario" y el "Constitucional", sin replantearnos seriamente el sistema de adiestramiento para el ejercicio de la judicatura (me remito al propósito a lo escrito por nuestro colega Alejandro Sáinz Arnaiz), y sin preguntarnos - y estar dispuestos a responder sinceramente- a qué responde el impulso reformador plasmado en el Espacio Europeo de Enseñanza Superior, el último, por ahora, de los quebraderos de cabeza de la casta profesoral. Mis felicitaciones más sinceras al profesor Alzaga por esta iniciativa, que deberían tener continuidad con otras en las que nos dediquemos a fondo a desentrañar el cómo y el para qué de la enseñanza del Derecho Constitucional.

Hay, pues, problemas de deslegitimación y de des-ubicación del juez constitucional ante la opinión pública. Entre otras cosas porque la gente del común y muy a menudo - lo constato con preocupación - los propios abogados, no acaban de entender la posición del intérprete supremo. Y tenemos, por último, la gran cuestión de la Constitución territorial, que es la que más se resiente de nuestra incapacidad para acometer una reforma, en un texto que es en esto, sobre todo, un texto sobrecargado de principios y escaso de reglas. Lo que hay en el Título VIII de decisiones cerradas y reglas claras es casi en su totalidad Derecho transitorio, esto es, hoy, Derecho muerto; un Derecho para el acceso a la autonomía, para la conversión de un Estado unitario en uno compuesto, cuyos principios han necesitado de una reconstrucción constante por parte del juez constitucional. Esto lo saben bien los norteamericanos, que lo dicen mucho cuando discuten el papel del Tribunal Supremo: una Constitución de principios, una Constitución "principialista", deposita demasiado poder en manos del juez constitucional, y con mayor razón si la posibilidad de la reforma está bloqueada. En cualquier caso, y para ir terminando, me parece que lo menos que puede decirse de un diseño del proceso de reforma estatutaria en el que se posibilita que la razón del intérprete último pueda entrar en conflicto con una razón que se ha ido decantando a través del proceso democrático en dos parlamentos y además mediante aprobación directa de los ciudadanos, es que es un pésimo diseño. ¿Nos hemos equivocado? No lo sé, pero la situación es ésa. Y según qué sea lo que esperamos de la aplicación judicial en tal coyuntura, así será nuestro entendimiento de lo que es la Constitución y el Derecho que la sustenta. Una posibilidad es entender el Derecho como un conjunto de normas coactivas, dotadas de sanción, en las que alguien tiene que imponer la palabra definitiva sobre su interpretación. La otra alternativa es concebir la vida constitucional como un diálogo argumental, como una búsqueda siempre provisional de soluciones para expectativas plurales, que incentiven el mayor compromiso posible con el marco jurídico que garantiza la posibilidad misma de encontrarlas. 


\section{MANUEL JIMÉNEZ DE PARGA}

Muchas gracias al profesor Revenga Sánchez. Y ahora, por último, intervendrá el profesor Lucas Murillo de la Cueva.

\section{PABLO LUCAS MURILLO DE LA CUEVA}

Quiero comenzar agradeciendo a los colaboradores de la UNED de que hayan pensado en mí para estar en esta mesa bajo la presidencia de Don Manuel Jiménez de Parga y con compañeros a los que aprecio extraordinariamente como a todos los que nos acompañan y lamento no haber estado esta mañana y no haber podido seguir las conferencias y los debates que se han producido.

Expresado este agradecimiento que me parece obligado abordo la cuestión tratando de limitarme al tiempo que nos han asignado. Al hablar de aplicación judicial creo que como han indicado mis compañeros de mesa yo también voy a tener que poner de manifiesto algunas cosas que parecen obvias. Refiriéndome a la aplicación que de la Constitución o del Derecho constitucional, si queremos decirlo así, llevan a cabo los juzgados y tribunales, es decir, prescindo en este momento de la que lleva a cabo el Tribunal Constitucional. Y a ese respecto cuando se trata de la aplicación por los juzgados y tribunales de las normas del Derecho constitucional lo primero que hay que decir, la primera obviedad, es que tanto el sujeto que lleva a cabo esa aplicación, es decir, el juez, como el órgano a través del cual lleva a cabo esta labor, el tribunal y su configuración orgánica, como el procedimiento a través de cual ejerce esa aplicación de la Constitución, todo eso en su conjunto es a su vez la primera manifestación evidente de aplicación judicial de la Constitución. La propia existencia, las propias características que lo distinguen, la forma en la que funciona o debe funcionar es una encarnación o una especie de encarnación de la Constitución; es como si dijéramos, la Constitución puesta en marcha. Y esto se ve clarísimamente: la separación de poderes, la posición del juez, la posición de las partes en un proceso, la fuerza de las decisiones judiciales. Creo que es evidente, pero creo que en este momento conviene decirlo. Otra cosa que también es evidente pero que hace falta recordarlo igualmente en línea con lo que se ha observado con anterioridad es que además dentro del diseño del constituyente la posición del juez o si se quiere la posición del poder judicial es una posición muy importante, puede incluso considerarse central desde la perspectiva del papel que desempeña la garantía del conjunto del sistema, incluso también desde la perspectiva que ofrece para los sujetos principales del sistema que son los ciudadanos: controla la legalidad de la actuación de los poderes públicos, preserva los derechos y los intereses de todos y particularmente preserva los procedimientos especiales, los derechos fundamentales. Entonces esa función de control de la legalidad de los poderes públicos que llega incluso a colaborar más allá de la legalidad, también la constitucionalidad, pues colabora con el Tribunal Constitucional en la activa- 
ción del control de constitucionalidad de las normas con fuerza de ley, aparte de las facultades de la interpretación conforme a la Constitución de las leyes le corresponde. Eso le supone una posición central al menos desde el punto de vista de la garantía del ordenamiento constitucional en la medida en que es el que sienta las bases sobre las que descansa todo el sistema. Y luego ya si observamos la actuación que lleva a cabo por debajo de la ley respecto de la actuación de todos los poderes públicos y también en relación con todos los conflictos que surgen entre los particulares, esta observación se corrobora. Y así resulta que a través de esas dos puertas de entrada que pueden considerarse el artículo 106 de la Constitución desde la perspectiva de los poderes, pero sobre todo el artículo $24 \mathrm{y}$ el derecho a la tutela judicial efectiva, nos encontramos que los jueces contribuyen mediante esa función de garantía a una aplicación cualificada, a una efectividad del conjunto del ordenamiento, también de la Constitución o en primer lugar de la Constitución y de las normas que desarrollan la Constitución. Es evidente, lo que pasa es que las cosas evidentes son a veces las que menos vemos, cuestas a veces percibirlas; ocurre que en ocasiones los árboles a veces no dejan ver el bosque.

Dicho esto, ¿̨cómo se aplica judicialmente la Constitución? Creo que vamos llegando a estas alturas, en el año 2007 a una situación en la que se aplica no sólo con habitualidad, sino también con naturalidad. Parece que es algo que está asumido. Y si respondemos a esta pregunta desde la perspectiva de la suerte que corren las resoluciones judiciales, las que dictan juzgados y tribunales del Poder Judicial, la suerte que tienen ante el Tribunal Constitucional al menos desde un punto de vista cuantitativo, tenemos que es un juicio muy favorable el resultado. Porque si no he mirado mal, tomando la memoria del año 2006 del Tribunal Constitucional resulta que se han anulado 92 resoluciones de órganos judiciales, 3 del Tribunal Supremo y luego repartidas. Pero en el año 2006 si vamos a la memoria del Consejo General del Poder Judicial se dictaron casi 8 millones de resoluciones judiciales. No son cantidades homogéneas y estos datos cuantitativos tampoco nos pueden llevar a extraer cuestiones exultantes. Pero si me parece que son muy significativas porque cada año y en la memoria del año 2006 nos dicen que han entrado en el Tribunal Constitucional 11.041 recursos de amparo. De nuevo, las cantidades no son homogéneas pero sí nos sitúan en un territorio para saber de qué estamos hablando. Y luego también de esas mismas memorias extraemos que los recursos de aparo se centran en invocaciones del articulo 24, del artículo 14 y del artículo 25. Prácticamente estas tres invocaciones agotan el recurso, cuantitativamente son muy reducidas todas las demás. ¿Qué conclusión podemos sacar de estas referencias? Pues que los principales defectos se producen más que en cuanto al fondo, en el procedimiento; mejor dicho, en el acceso, a veces problemas de legitimación, en el procedimiento porque algunas veces funciona mal, y en la Administración de Justicia se producen situaciones de indefensión, en menor medida en relación con la motivación de la prueba. También es cierto en relación con lo que se refiere a la formación de voluntad del órgano judicial, problemas de motivación y de congruencia de las resoluciones. Pero yo creo que eso se va reduciendo porque 
aunque sean muchas las quejas que apuntan en estas direcciones, sin embargo las que prosperan, ya hemos visto, son escasísimas. Esto no quiere decir que vivamos en el mejor mundo de los posibles, pero si quiere decir que al menos desde la perspectiva que pudiera tomarse, es decir mirando desde el Tribunal Constitucional y desde el enjuiciamiento del amparo, el balance para la labor de los jueces y tribunales no tiene que ser negativo salvo en algo de lo que adolece todo el sistema que desgraciadamente afecta también al Tribunal Constitucional, que es la lentitud, la incapacidad del sistema para digerir en tiempo razonable el volumen de demandas que los ciudadanos conscientes de que son titulares de derechos, le plantean.

En cualquier caso, dejando esto al margen, que tiene una problemática particular, lo que sí creo que puede decirse de lo anterior, es que obedece a algunos factores que tiene que ver con el conocimiento de la disciplina y que también tienen que ver con la enseñanza de la misma en mi opinión. En primer lugar, lo primero que creo que es indiscutible es la fuerza normativa de la Constitución, la cual a su vez guarda relación con el hecho de que es una Constitución que se ajusta a los problemas y necesidades de la sociedad que rige. Aúna adecuación, una coherencia que a su vez me lleva a decir que obedece en mi opinión al método con el cual se elaboró. Y naturalmente también esto que estoy diciendo tiene mucho que ver con la labor que ha venido desarrollando el Tribunal Constitucional, sobre todo en su primera andadura, pero luego en la restante, al definir el sentido de las normas constitucionales y al definir el sentido de los derechos que la propia Constitución reconoce. Y eso forma parte ya de un acervo adquirido que asumen o deben asumir quienes aplican las normas jurídicas desde los juzgados y tribunales. Los cuales también creo que recientemente van asumiendo o han asumido, ya no diré si eso está conseguido en su totalidad o es un proceso permanente, la condición de servidores de la ley, de servidores de la Constitución, con la salvedad siempre de la lentitud.

En los procesos observamos, y a demás a veces en procesos que uno no se imagina por la materia sobre la que versen, cómo sobre todo los principios que reconoce la Constitución o que derivan de la propia Constitución están presentes en el razonamiento judicial. Incluso en ocasiones observamos cómo los tribunales se mueven con comodidad, con cierta soltura se podría decir, en ese terreno. Y gracias a esa utilización que de los principios consiguen introducir criterios de racionalidad jurídica en sectores que a veces son difíciles de comprender porque la ordenación es compleja y no siempre muy coherente. Pero en conjunto la situación debería llevar, si no fuera por el problema de la lentitud, lentitud absolutamente intolerable, ciertamente más acusada en unos órdenes que en otros, en unas materias que en otras, a una valoración favorable, a una valoración positiva. Valoración positiva que por otro lado se puede acompañar como ya ha indicado antes Miguel Revenga del que no vivimos en un escenario que sea peor del que ocurre en oros lugares. Esta referencia a lo que sucede en otros lugares o en otros países, igual en nosotros está más acentuada que en otras experiencias seguramente porque hace algunos años 
aquí no había nada, y como no había nada, había que mirarlo en otros sitios. Creo que hoy en día las cosas no son necesariamente mejores en otros lugares y puede incluso que en muchos aspectos sean mejores aquí. Y eso explica que así nos miren, como ciertamente nos miran otros que antes no nos miraban.

Entonces para concluir ya que el tiempo se me va, ¿qué conclusión o qué consideración podría añadir en coherencia con lo que han dicho los otros componentes de la mesa a este respecto a propósito de la enseñanza del Derecho constitucional? Creo que hemos llegado a un punto en el cual la asunción, la penetración de los preceptos constitucionales en todas sus dimensiones es tan intensa e irradia de una forma tan horizontal que está presente prácticamente en todas partes. Y de tal modo en cualquiera de las resoluciones judiciales está presente esa penetración y por tanto está presente en la aplicación que al caso concreto se hace del ordenamiento jurídico, en los temas cono dije más variados. Por eso creo que estamos llegando a un punto en el cual se puede entender o se puede comprender mejor el sentido de los preceptos constitucionales y de las propias instituciones a través de esas resoluciones judiciales o si no se puede comprender mejor si desde luego es un instrumento muy útil para entender el sentido verdadero del ordenamiento constitucional. Se trataría por tanto si se considera por tanto los pronunciamientos de los tribunales y los pronunciamiento sobre todo del Tribunal Supremo, las sentencias que dicta las cinco salas del Tribunal Supremo, a través de ellas pero a través de las de otros órganos jurisdiccionales, tendríamos una suerte de visión desde abajo, una visión si se quiere microjurídica de cómo se vive la Constitución. Pero es que esa visión nos está diciendo en realidad cómo es o cómo se está viviendo la Constitución. Nos está poniendo de manifiesto, y desde luego también lo hace el Tribunal Constitucional sin ninguna duda, pero es que sus sentencias son muy pocas, y sin embargo las sentencias del Tribunal Supremo son muchísimas, y si extendemos la mirada a otros tribunales son todavía muchas más, tribunales que pueden dictar sentencias que luego no se recurren, o porque no son recurribles o porque no las recurren las partes. Eso nos está poniendo de manifiesto una visión de la realidad que el teórico, que el estudioso tiene que tener presente para ofrecer con la teoría conceptos que permitan ordenarla, que la comprendan mejor, conjugar con ese instrumento, formar a partir de esos materiales teoría y con esa teoría comprender mejor la realidad. Y así permitiéndome, y ustedes me disculparán, jugar con las dos palabras de teoría y realidad constitucional quiero concluir mi intervención.

\section{MANUEL JIMÉNEZ DE PARGA}

Muchas gracias al profesor Lucas Murillo de la Cueva. Abrimos ahora un tiempo de diálogo. El profesor Aragón ha pedido la palabra. 


\section{MANUEL ARAGÓN REYES}

Me he quedado con mucho gusto en esta mesa porque por razones obvias me atraía. Y como es natural aprovecho para intervenir, aunque intentaré no extenderme demasiado. La aplicación judicial del Derecho constitucional, me parece que a diferencia de cuando esta mañana hablábamos del objeto del Derecho constitucional que no es solamente la Constitución sino otras muchas normas más del ordenamiento, podemos ceñirla a la aplicación judicial de la Constitución. No estoy reduciendo el ámbito del Derecho constitucional sino el ámbito de nuestro debate. Porque obviamente las demás leyes, es decir, la ley, se ha aplicado siempre; lo que es nuevo es la aplicación judicial de la Constitución; es nuevo aquí porque en Europa como sabemos se adopta después de la Segunda Guerra Mundial el modelo constitucional, la concepción constitucional norteamericana: la Constitución es norma jurídica aplicable por todos los jueces y tribunales, es Derecho, y como tal judicialmente aplicable. No solamente por un tribunal especializado — sistema kelseniano- sino por todos los jueces y tribunales porque vincula a todos los poderes públicos. Ahora bien, esa realidad, que es la de nuestros días, como ha dicho Pablo Lucas, que lo conoce mejor que nadie puesto que ejerce jurisdicción ordinaria, se practica en España a diario en millones de sentencias porque en grandísima parte de las sentencias de todos los órdenes jurisdiccionales y de todas las instancias rara es la que no hace apelación a preceptos constitucionales. Esa realidad plantea, vamos a decirlo así, unos problemas que nuestro ordenamiento ha intentado ofrecer los instrumentos para resolverlos. Y esos problemas son que como la Constitución tiene una textura distinta, no en todos sus preceptos, obviamente, pero sí en gran parte de sus preceptos, a la de las leyes ordinarias (estoy simplificando), la aplicación de la Constitución, es decir, la interpretación de la Constitución, tiene tales peculiaridades que si estuviese en la libre capacidad de interpretación de todos los jueces y tribunales podía conducir a un sistema de una cierta inseguridad y desigualdad. Esto lo tienen resuelto en Norteamérica, desde que surge esa idea de la Constitución como Derecho sin más, Derecho superior, pero Derecho tan aplicable como todo lo demás, a través del sistema del precedente. En España y en general en el modelo europeo de justicia constitucional, se tiene a través de otro sistema que se parece y es a través de que existe un Tribunal Constitucional que no solamente es el supremo en la interpretación-aplicación de la Constitución sino el especializado en la interpretación constitucional. No nos olvidemos nunca eso: no es solamente el supremo, sino el tribunal especializado en esto tan singular y tan difícil - hablaba Ángel de la ponderación, etc - como es la interpretación-aplicación de la Constitución.

Y con gran sabiduría la Ley Orgánica del Poder Judicial, desde que se dictó su primer texto en 1985, ofrece en su artículo 5.1 la regla para evitar la inseguridad y desigualdad que podría derivarse de que millones de resoluciones judiciales interpreten-apliquen la Constitución. Y es la regla, que todos sabemos, de que los jueces y tribunales interpretarán y aplicarán las leyes y regla- 
mentos de conformidad con los preceptos y principios constitucionales, conforme a la interpretación de los mismos que resulte de las resoluciones dictadas por el Tribunal Constitucional en todo tipo de procesos. Ese no es exactamente el precedente norteamericano, pero sí la determinación, clara, de los efectos vinculantes de la doctrina del Tribunal para todos los jueces y tribunales. Lo que pasa es que esa regla necesita de un instrumento de control. Y ese instrumento de control es el amparo, no hay otro. De ahí que el modo de conseguir que esa disposición legal tenga efectividad práctica es justamente el amparo, un amparo que reducido por la reforma última de la Ley Orgánica del Tribunal justamente a esa dimensión, no de amparo - tutela (como antes) sino de amparocontrol de la interpretación de la Constitución por los jueces y tribunales, es a mi juicio el instrumento idóneo. Así, además, desaparecerá esa sobrecarga de trabajo del Tribunal que ha tenido hasta ahora a través de un amparo-tutela muy benéfico en los primeros diez, quince años de justicia constitucional, pero que hoy es una verdadera carga insoportable, para quedar limitado el amparo a lo que a mi juicio el amparo debe ser: el control de la unificación de la interpretación constitucional, de la aplicación constitucional, por todos los jueces y tribunales. Porque justicia constitucional la ejercen todos los jueces y tribunales, porque justicia constitucional es simplemente la aplicación judicial de la Constitución. En ese punto nuestro sistema es difuso. El Tribunal tiene el monopolio de determinados procesos, pero la aplicación de la Constitución la tienen todos los jueces. Y el amparo, por eso quería llamar la atención, reducido a esa dimensión objetiva, si al final se gestiona bien, se practica bien, pasan unos años y arraiga en nuestra cultura jurídica que a eso y solo a eso queda reducido el amparo, puede ser un útil instrumento de control de esa sabia y necesaria previsión de que todos los jueces y tribunales estén vinculados a la doctrina del intérprete supremo de la Constitución, que no es solamente el supremo sino el especializado porque tiene por cometido justamente eso tan especial como es sentar la interpretación constitucional.

Por último, a veces no se repara en que el balance de la aplicación judicial de la Constitución es en España extraordinariamente positivo como lo prueba el siguiente dato: de las que tú has dicho, cinco millones, me parece, ocho millones de decisiones judiciales dictadas al año, llegan en amparo diez mil, el año pasado once mil y pico. Tengamos en cuenta que aunque el amparo solamente protege los derechos de la sección primera, el control de la aplicación judicial de la Constitución puede ir siempre a través del art. 24, o sea que en el fondo podían ir muchos más amparos que los referidos a los derechos sustantivos de la Sección $1^{\mathrm{a}}$. Si en principio solamente van diez u once mil pese a que todo abogado y todo cliente si cree que puede acudir al Tribunal Constitucional acude, quiere decir que solo diez u once mil, de los millones de resoluciones judiciales que se dictan al año han entendido las partes cuando son firmes que han producido vulneración o mala o defectuosa aplicación de la Constitución por los jueces. Insisto, porque siempre se puede ir por el art. $24 \mathrm{o}$ el art. 14. Y de esos once mil se admiten el año pasado el tres por ciento. De ese tres por ciento se estiman las dos terceras partes, el dos por ciento. Pues bien, si pen- 
sáramos que sólo el dos por ciento de los recursos de amparo presentados que son el 0,003 \%, de las resoluciones judiciales firmes dictadas en España, han ido al tribunal y han sido revocadas, rectificadas, por entender que no se ha aplicado bien la Constitución, nuestra aplicación judicial de la Constitución creo que es una de las más, no voy a decir perfecta, pero sí adecuadas del mundo civilizado. Si las decisiones del Tribunal Constitucional, hagamos abstracción ahora de Estrasburgo, fueran revisadas por otro tribunal superior y solo al $0.003 \%$ de sus resoluciones se entendiera que son incorrectas, sería el mejor tribunal constitucional del mundo. Esto es algo que debemos tener muy en cuenta: la fructífera, la buena aplicación judicial de la Constitución que se está haciendo en España por todos los jueces y tribunales. Y nada más.

\section{MANUEL JIMÉNEZ DE PARGA} venir.

Muchas gracias al Profesor Aragón. El Profesor López Guerra quiere inter-

\section{LUIS LÓPEZ GUERRA}

Las ponencias presentadas han puesto el acento en la fuerza normativa de la Constitución, y en el papel de los órganos judiciales, tanto en la jurisdicción constitucional como en la ordinaria. Yo quisiera proponer algunas dificultades. Las normas constitucionales tienen muchas texturas: unas enuncian principios, otras establecen reglas. En este último caso, es posible determinar en forma aceptablemente concreta el mandato específico que se establece. Pero las normas que enuncian principios, o valores, tienen una densidad bastante más relativa, son mucho más imprecisas. Y sin embargo, esas normas muchas veces son utilizadas por los Tribunales en forma decisiva como puntos de referencia o como criterios, o como parámetros como se dice ahora, para la aplicación del Derecho. Pero la interpretación de los valores es algo bastante difícil y abierto a opiniones, y por eso en ocasiones no puede adivinarse por dónde puede salir el tribunal en cuestión. Creo que la concepción predominante en España del significado de de la fuerza normativa de la Constitución y de su aplicación judicial se deriva de la influencia de doctrinas y ordenamientos externos; valga como ejemplo lo que ha supuesto la influencia alemana en toda la jurisprudencia del Tribunal Constitucional y en la concepción de la Constitución como orden de valores. También habría que destacar la influencia norteamericana, la idea de la Constitución como living Constitution y la posibilidad de extraer mandatos de la misma. Pero no olvidemos que el contexto alemán o el contexto americano tienen peculiaridades que quizá no se den en nuestro contexto, lo que falsea la adopción de esos modelos. Por ejemplo, en el caso norteamericano, es fundamental la idea del judicial restraint, la prudencia de los tribunales, así como la existencia de convenciones constitucionales gene- 
ralmente aceptadas, que aportan una cierta seguridad en cuanto a interpretación de la Constitución. En el caso alemán es evidente que existe una comunidad de valores, y yo me atrevería a decir, también de convenciones constitucionales, generalmente aceptadas después de la experiencia histórica que supuso el nazismo, y que dan lugar a una homogeneidad de valores traducida en un funcionamiento regular y sin grandes problemas del Tribunal Constitucional. Cabe preguntarse si este tipo de condiciones se dan en nuestro país. Pero además hay expresiones concretas de la dificultad de la aplicación judicial de la Constitución. Por ejemplo, respecto a la técnica de la interpretación conforme. De acuerdo en que si existen diversas interpretaciones de una norma cabe presumir que la adecuada a la Constitución será la que el legislador efectivamente quería; incluso en algunos casos cabrá forzar algo la literalidad del texto. Pero habría que preguntarse: hasta qué punto es compatible con la exigencia de la seguridad jurídica del ciudadano el que lo que dice un texto legal no responda a su sentido literal inmediato, sino a la modulación que supone la interpretación "conforme". Pero no solo eso, sino que se plantean también problemas desde la perspectiva del principio democrático: cabe en muchos casos concluir que la interpretación conforme establecida por los tribunales no coincide con lo que quería el legislador. Incluso en muchos casos no podrá excluirse que si el legislador hubiera sabido que el Tribunal Constitucional iba a interpretar de tal modo una norma, hubiera preferido no legislar.

Otro punto a debatir sería el coste de las sentencias. Cuando se dicta una sentencia sobre temas de igualdad, el remedio de la desigualdad normativa suele consistir en equiparar a todo el mundo "por arriba", esto es, unificar todos los tratamientos en el nivel más favorable. Y ello puede conllevar unos costes muy notables con respecto a la distribución de los recursos públicos. Este tema se ha planteado en otros ordenamientos, (sobre todo latinoamericanos, y también en Italia) en los que de la interpretación efectuada por los tribunales se han deducido mandatos constitucionales que suponen cargas para el erario público, interpretándose que unos derechos prestacionales sociales resultan inmediatamente de mandatos constitucionales. Una decisión de un tribunal constitucional en esta línea supone una redistribución de recursos públicos, en el sentido de que, como consecuencia de una sentencia, determinados fondos deben destinarse a la vivienda, por ejemplo, y no a carreteras o a sanidad. A cierta distancia de esos casos, cabría señalar, por ejemplo, que cuando el Tribunal Constitucional español decidió la equiparación en cuanto a subrogación de alquileres entre matrimonios y parejas que vivieran more uxorio, eso suponía tomar una decisión, con consecuencias económicas amplias, entre los intereses de los arrendadores y los intereses de los arrendatarios. Son problemas o dudas que a uno le surgen sobre los límites de la interpretación judicial. 
MANUEL JIMÉNEZ DE PARGA

Muy bien. Veo que llegan ya los compañeros de otras Comisiones. Antes de ello daremos la palabra a la profesora María Luz Martínez Alarcón de la Universidad de Castilla la Mancha que ha presentado una comunicación a esta comisión.

\section{LUZ MARTÍNEZ ALARCÓN}

Antes de comenzar con esta breve exposición, me gustaría felicitar muy sinceramente al director de las Jornadas por esta iniciativa y a la organización de las mismas por un trabajo realmente bien hecho. Tampoco puedo dejar de agradecer a todos ellos su invitación para participar en las mismas. Mi comunicación, que lleva por título "La aplicación judicial del Derecho constitucional,, está dividida en tres partes claramente diferenciadas. En la primera, pongo de manifiesto que un entendimiento concreto del Derecho desemboca en un concreto entendimiento del quehacer de los juristas prácticos. En efecto, la comprensión de la labor del juzgador ha sido diversa según se haya sostenido una tesis objetivista o cognoscitiva, una tesis subjetivista o escéptica, o una tesis intermedia o ecléctica del ordenamiento jurídico. Esta última, por otra parte, que es la tesis propia del positivismo jurídico moderado y del consiguiente reconocimiento de la discrecionalidad judicial, es la postura dominante en la literatura jurídica contemporánea y, en mi opinión, la más convincente. En la segunda, afirmo que el constitucionalismo de la segunda mitad del siglo XX ha fortalecido la tesis del positivismo jurídico moderado de la discrecionalidad judicial. La especificidad del texto constitucional (validez derivada de su legitimidad democrática, estructura abierta y contenidos sustantivos y principiales) aporta un margen de discrecionalidad notable a su intérprete cuanto intenta dotarlo de significado. En la tercera, sostengo que aceptar la tesis de la discrecionalidad judicial no supone admitir un modelo de juez activista e incontrolado y que, desde este punto de vista, el discurso de la ponderación, con el que se pretende establecer una relación de precedencia condicionada entre los principios que entran en conflicto, y, más concretamente, el parámetro argumentativo del juicio de proporcionalidad, contribuyen a introducir racionalidad en el marco de la decisión judicial. Precisamente, esta última parte concluye con una reflexión sobre el principio de proporcionalidad y su supuesta convivencia con el contenido esencial de los derechos fundamentales sosteniendo que el entendimiento relativo del mismo parece más conforme con nuevo constitucionalismo de principios. En cualquier caso, como ya indico en el texto, estas líneas no son sino unas primeras reflexiones sobre este complejísimo tema de la interpretación constitucional y así deben ser tenidas en cuenta por todo aquellos que decidan leer estas páginas. 


\section{MANUEL JIMÉNEZ DE PARGA}

Gracias. Muy bien expuesto, rápidamente expuesto. Tomamos ahora un receso de un minuto a la espera de que llegue el conjunto de colegas de otras comisiones. Procederemos en ese momento y tal como se señala en el programa a la redacción de las conclusiones de las tres comisiones y, finalmente, la clausura a cargo de la Decana de esta Facultad.

\section{CONCLUSIONES Y CLAUSURA}

\section{ANA ROSA MARTÍN MINGUIJÓN 6}

Buenas tardes a todos. Tiene la palabra el Profesor Oscar Alzaga Villaamil, Catedrático de Derecho Constitucional de esta Universidad y Director de la Revista Teoría y Realidad Constitucional organizadora de estas Jornadas.

\section{OSCAR ALZAGA VILLAAMIL}

Querida Decana. Muchas gracias. Nos honra presidiendo en esta clausura la Profesora Ana Rosa Martín Minguijón, Decana de esta Facultad de Derecho de la Universidad Nacional de Educación a Distancia que nos ha acogido este día de hoy. Ha tenido la bondad de venir esta tarde para estar con nosotros en este acto. Se lo agradezco particularmente. Solo quiero en dos palabras comentar la metodología que vamos a seguir, aunque con brevedad. No está constitucionalizado el derecho al descanso el viernes por la tarde pero en una democracia avanzada se llegará a ello

Pero antes de nada quiero decir aquello para lo que he pedido la palabra y es que estas Jornadas han sido posible, pudiendo participar ciento catorce profesores de la asignatura, gracias a dos circunstancias. Una vocación hacia la disciplina del Derecho Constitucional a prueba de bombas y en segundo lugar una dedicación generosa de toda la gente del Consejo de Redacción de la revista: y especialmente de los profesores más jóvenes del departamento: María Núñez, Isabel Martín, María Salvador, que es quien propuso que comiéramos en el Museo del Traje y organizó la visita, reflejo de su sensibilidad natural e Isabel Serrano, Sabela para nosotros, que nos la captó la Complutense y se ha ido de profesora titular a tal Universidad pero sigue viniendo todas las semanas aquí a trabajar en la revista Teoría y Realidad Constitucional y que se ha dejado literalmente media vida en la Organización de las Jornadas.

Pero especialísimamente a dos personas que si no mencionara no tendría el más mínimo sentido de justicia: los profesores Jorge Alguacil y Fernando Reviriego, secretarios de nuestra publicación.

6 Decana de la Facultad de Derecho (Universidad Nacional de Educación a Distancia). 